\title{
In vivo Remineralization Using a Sustained Topical Fluoride Delivery System
}

LEWIS J. ABRAHAMS,* MASA YONESE, WILLIAM I. HIGUCHI, JEFFREY L. FOX, and GERALD T. CHARBENEAU

Department of Operative Dentistry, School of Dentistry and College of Pharmacy, The University of Michigan, Ann Arbor, Michigan 48109

The efficacy of a new remineralization system was determined in vivo by maintaining a low concentration of approximately $1 \mathrm{ppm}$ fluoride for 48 hrs against a demineralized human tooth. Human subjects were selected who wore removable partial dentures containing two or more of the demineral. ized teeth with film system. The findings indicate levels of fluoride uptake to 500 ppm at 50 micron depths in experimental sites.

J Dent Res 59(3):583-587, March 1980

\section{Introduction.}

Many researchers have demonstrated that, in both laboratory and clinical investigations, substantial amounts of fluoride are deposited in human enamel from topical treatments. Unfortunately, a considerable portion of the fluoride deposited from a topical treatment leaches away in a short period of time, and only a small amount is permanently retained..$^{1-3}$ To increase the amount of retained fluoride in enamel, multiple treatments, as well as sealants and etching, have been studied. 4-13 The use of a single application which will provide a prolonged and unhindered treatment appears to be essential to meet the needs of dental health programs.

The purpose of this study was to deter-

Received for publication May 24, 1979

Accepted for publication October 8, 1979

*To whom correspondence should be addressed. Present address: Major Lewis J. Abrahams, USAF Medical Center/SGD, Scott Air Force Base, IL 62225 .

This investigation was based on a thesis required for partial fulfillment of the M.S. Degree in Restorative (Operative) Dentistry by L. J. Abrahams.

The investigation was supported in part by Grant DE- 04600 from the National Institute of Dental Research.

This paper was presented at the 57 th General Session of the IADR, March 29-April 1, 1979, New Orleans, LA (Abstract \#627).

mine, in a pilot clinical program, the efficacy of a new remineralization system employing calcium fluoride. We also tested the hypothesis that a film capable of sustaining a local aqueous fluoride concentration of approximately $1 \mathrm{ppm}$ and permeable to water, calcium, and phosphate ions can remineralize demineralized human tooth enamel with prolonged contact.

\section{Materials and methods.}

The material consisted of 11 pairs of homologous contralateral non-carious teeth (extracted for orthodontic expediency). One tooth from each pair was used in the clinical study. The other tooth was used for baseline evaluation of fluoride content for each pair. Residual tissue was cleaned from the tooth with Bunting scalers 5 and 6 , and the tooth was brushed under warm tap water with a soft toothbrush. Each pair was individually sterilized by exposure to ethylene oxide gas ${ }^{\S}$ for five hrs at $63^{\circ} \mathrm{C}, 40 \%$ humidity and at eight pounds psi pressure. To verify the sterilization procedure, two additional non-carious bicuspids were sterilized and then incubated at $37^{\circ} \mathrm{C}$ for $48 \mathrm{hrs}$ in tripicate soya culture media. The results were negative, since no bacterial growth was observed. The verification procedure was repeated after the 11 pairs of teeth were sterilized, and the same negative results were obtained. The enamel surface had a prophylaxis treatment with a non-fluoride pumice.

The roots of the teeth were sectioned with a carborundum disk approximately $2 \mathrm{~mm}$ from the cementoenamel junction. The teeth were then covered with a blue inlay wax, except for a region of approximately $0.20 \mathrm{~cm}^{2}$ in the center of the buccal and lingual surfaces.

\footnotetext{
$\S$ Penngas, Pennsylvania Engineering Co., Phila-
} delphia, PA 
The exposed portion of each tooth was then demineralized in a $16 \%$ partially saturated buffer solution $(\mathrm{pH}=4.5,0.1 \mathrm{M}$ acetate, $3.5 \mathrm{mM}$ Ca and $\mathrm{PO}_{4}$, adjusted to ionic strength 0.5 with $\mathrm{NaCl}$ ) for $48 \mathrm{hrs}$. One tooth from each pair was maintained in the laboratory in a high humidity environment, which was obtained by placing a folded $2 \times 2$ gauze wet with distilled water at the bottom of a closed glass bottle. The tooth was kept out of contact with the gauze. In this manner, the tooth was prevented from becoming dehydrated. The other tooth from each pair had the wax removed and was used in the clinical study.

Four subjects, ranging from 42 to 74 years of age, were selected. Each subject had at least two posterior edentulous sites on either arch. There were no significant contributing findings in the health histories. Alginate impressions and stone casts were made of the edentulous and opposing arches. Two male subjects each wore a maxillary appliance, while two female subjects each wore a mandibular appliance. Two, three, or four demineralized teeth were adapted to the ridge area of each subject.

The teeth were placed on one or both sides of the arch. The remineralization film was applied to either the facial or lingual surface of the teeth as shown in Figs. 1a and b. The remineralizing system consisted of a water-permeable cellulose dialysis film ${ }^{\dagger}$ with $1 \mathrm{mg}$ of $\mathrm{CaF}_{2}$ powder placed on its surface. The powder and film were sealed against the tooth with a dimethacrylate resin $\ddagger$ as shown in Figs. $2 a$ and $b$. The $\mathrm{CaF}_{2}$ powder had been ground to a particle size of 50 microns and filtered with a \#270 micromesh. The corresponding buccal or lingual surface of the adjacent tooth served as the control (See Figs. la and b). Wrought wire clasps, using 0.022-inch-round orthodontic wire, were adapted for retention. Coldcure acrylic resin ${ }^{* *}$ was used to form the denture base for the removable partial dentures.

Each subject was instructed not to remove the denture except for cleaning after meals. The appliance was worn during the

\footnotetext{
†Dialysis Bag, Spectrum Medical Industries, Los Angeles, CA

\$Endur-M by ORMCO, Glendora, CA

**Perm repair and rebase cold cure acrylic resin, Hygienic Manufacturing Co., Akron, $\mathrm{OH}$
}

night. The denture and teeth were cleaned lightly under warm water only. The subject's own dentition was cleaned with a soft toothbrush and baking soda. No toothpaste was used. The denture was worn for $48 \mathrm{hrs}$.

After that time period, the teeth were removed and sectioned with a carborundum disk into facial and lingual halves. The film was removed from the experimental sites. The segments were again covered with a blue inlay wax, except for the region which had originally been exposed for demineralization. All sites were rinsed for a short period of time with double distilled water. The experimental sites with the remineralization system were brushed lightly for five secs to remove residual $\mathrm{CaF}_{2}$ powder.

Five enamel layers, approximately 5,10 , 20,30 , and 30 microns thick were etched off each tooth by exposing the enamel to $1 \mathrm{ml} 0.5 \mathrm{M}$ perchloric acid for about 30 , $60,120,200$, and 200 secs, respectively. The enamel was then washed with a $1 \mathrm{ml}$ volume of double distilled water which was added to the original sample. The fluoride concentration was determined with a fluoride electrode ${ }^{\dagger \dagger}$

The amounts of fluoride uptake in the experimental and control teeth were compared using the nonparametric MannWhitney $U$ Test to determine if any significant differences existed.

\section{Results.}

The results are summarized in Table 1 and Fig. 3. When the experimental surfaces were analyzed $48 \mathrm{hrs}$ after a single application of the experimental fluoride delivery system, the mean fluoride uptake in the first enamel layer was $600 \mathrm{ppm}$. The uptake was significant when compared to the control surfaces $(p<0.01)$. Also, the fluoride uptake became highly significant $(p<0.001)$ when the second through fifth enamel layers were analyzed with values of 800 ppm, $500 \mathrm{ppm}, 250 \mathrm{ppm}, 150 \mathrm{ppm}$, respectively. The depths reported in Fig. 3 represent the midpoints for each successive enamel layer. The differences between etched enamel layer thickness in the base-

†† Model 96-09 Combination Fluoride Electrode used in conjunction with a Model $701 \mathrm{~A}$ Digital $\mathrm{pH} / \mathrm{mv}$ Meter, Orion Research, Inc., Cambridge, MA 
TABLE I

FLUORIDE CONCENTRATIONS (PPM) IN FIVE SUCCESSIVE SURFACE LAYERS (MICRONS) OF UNTREATED DEMINERALIZED TEETH (BASELINE); DEMINERALIZED TEETH AFTER TREATMENT FOR 48 HRS WITH SALIVA AS THE ONLY REMINERALIZATION SYSTEM (CONTROL); AND DEMINERALIZED TEETH AFTER TREATMENT FOR 48 HRS WITH EXPERIMENTAL REMINERALIZATION SYSTEM (EXPERIMENTAL).

\begin{tabular}{|c|c|c|c|c|c|c|c|}
\hline \multirow[b]{2}{*}{ Layer } & \multirow[b]{2}{*}{$\begin{array}{l}\text { Number of } \\
\text { tooth } \\
\text { surfaces }\end{array}$} & \multicolumn{2}{|c|}{ Base $(n=11)$} & \multicolumn{2}{|c|}{ Control $(n=11)$} & \multicolumn{2}{|c|}{ Experimental $(n=11)$} \\
\hline & & $\begin{array}{c}\text { Mean } \\
\text { (microns) } \\
\text { Layer } \\
\text { Thickness }\end{array}$ & $\begin{array}{l}\text { Mean } \\
\text { F. Conc. } \\
\text { ppm }\end{array}$ & $\begin{array}{c}\text { Mean } \\
\text { (microns) } \\
\text { Layer } \\
\text { Thickness }\end{array}$ & $\begin{array}{l}\text { Mean } \\
\text { F. Conc. } \\
\text { ppm }\end{array}$ & $\begin{array}{c}\text { Mean } \\
\text { (microns) } \\
\text { Layer } \\
\text { Thickness }\end{array}$ & $\begin{array}{l}\text { Mean } \\
\text { F. Conc. } \\
\text { ppm }\end{array}$ \\
\hline 1 & 33 & 5 & 474 & 5 & 713 & 5 & 1100 \\
\hline 2 & 33 & 11 & 381 & 9 & 540 & 10 & 1216 \\
\hline 3 & 33 & 20 & 299 & 19 & 266 & 19 & 789 \\
\hline 4 & 33 & 31 & 282 & 28 & 242 & 29 & 549 \\
\hline 5 & 33 & 33 & 144 & 33 & 170 & 32 & 303 \\
\hline
\end{tabular}

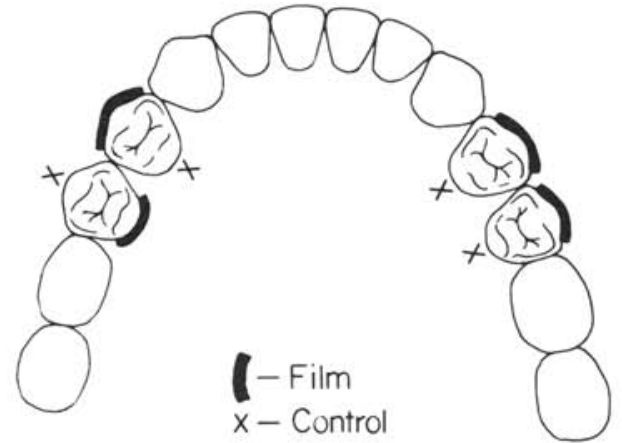

Fig. 1a - Schematic placement of remineralization system for appliance worn by Patient $\# 3$.

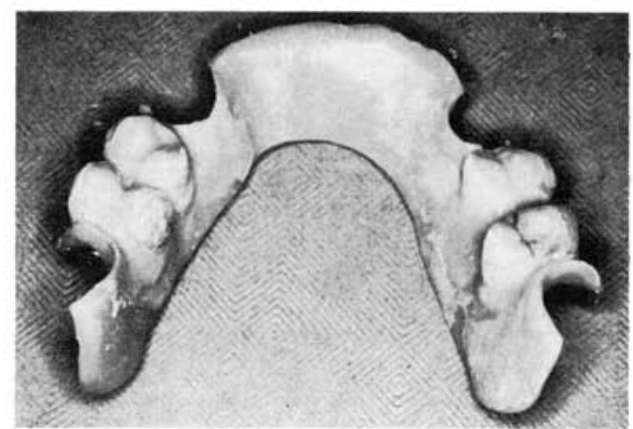

Fig. 1b - Photograph of appliance worn by Patient \#3.

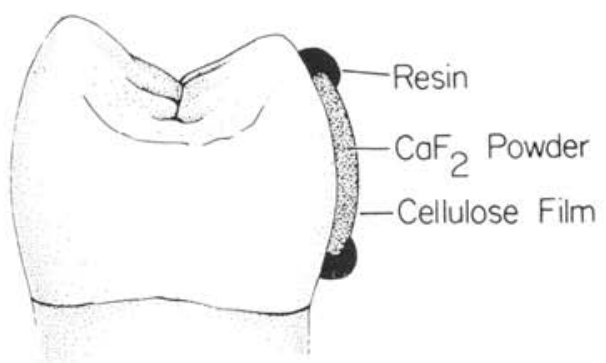

Fig. 2a - Schematic side view of remineralization system on the lingual surface of a bicuspid.

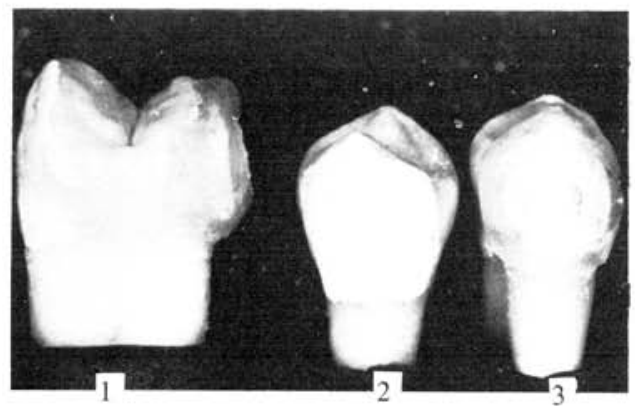

Fig. $2 b-(1)$ Side view with film on lingual surface and demineralized facial surface; (2) front view of a demineralized surface; and (3) front view of a demineralized surface with film system. 


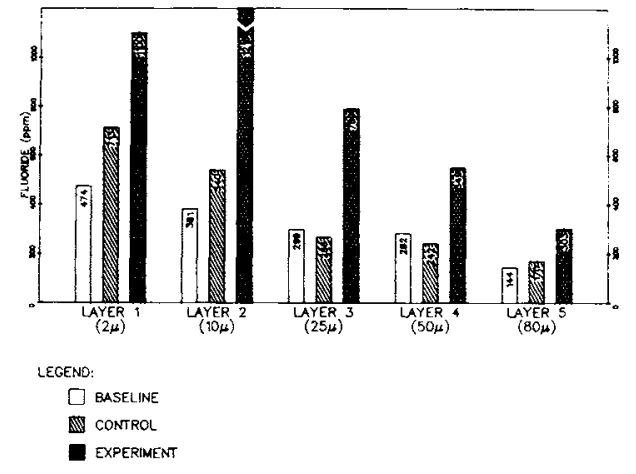

Fig. 3 - Fluoride concentrations (ppm) in five successive layers of baseline, control, and experimental surfaces. The number in parentheses represents the mid-point depth (in microns) for each layer. $\mathrm{N}=11$ for each column.

line, control, and experimental groups were not statistically significant $(p>0.05)$.

Both female subjects who wore the mandibular appliances had non-fluoridated water sources. However, using the MannWhitney $U$ Test, no significant difference $(p>0.05)$ was found in fluoride uptake for both control and experimental surfaces between patients living in fluoridated and non-fluoridated areas. Therefore, the results of maxillary and mandibular appliances could be summarized together. Furthermore, no significant difference $(\mathrm{p}>0.05)$ was found in fluoride uptake when comparing facial with lingual surfaces for either control or experimental sites. Thus, the data for maxillary, mandibular, facial, and lingual sites could be tabulated together to determine if there was statistical significance in fluoride uptake in enamel layers one through five, as shown in Table 1.

\section{Discussion.}

These results support the hypothesis that an artifically demineralized tooth surface or an incipient carious lesion may be relatively rapidly remineralized in vivo with an appropriate delivery system. In previously reported studies, ${ }^{14,15}$ it was shown that both demineralized bovine teeth and human teeth are rapidly remineralized $(\sim 24 \mathrm{hr}$ or less) when the solution conditions correspond to a fluorapatite activity product $\left(\mathrm{K}_{\mathrm{FAP}}=\mathrm{a} \frac{10}{\mathrm{Ca}}\right.$ a $\left.\frac{6}{\mathrm{PO}_{4}} \mathrm{a} \frac{2}{\mathrm{~F}}\right)$ of around $1 \mathrm{x}$ $10^{-108}$. The deposited mineral phase in these experiments was shown to possess the fluorapatite stoichiometry both by the perchloric acid etch method and by the electron microprobe assay.

Thermodynamic calculations show that, when $\mathrm{CaF}_{2}$ is added to saliva, the $\mathrm{K}_{\mathrm{FAP}}$ value for the system would be in the neighborhood of $1 \times 10^{-108}$, and it is relatively independent of $\mathrm{pH}$ in the 5 to 7 range. This, then, has been the basis for the rationale that $\mathrm{CaF}_{2}$, together with saliva, may be an effective remineralization system. In vitro experiments ${ }^{15}$ showed that this is so, and the present data support the in vivo applicability of the concept.

Before this approach may be considered for human therapeutic applications, answers to two questions should be found. One of these is whether the remineralization has significantly enhanced the tooth resistance to caries. The other is the retention of the remineralized phase and, therefore, the question of the frequency of application.

\section{Conclusions.}

A concept for rapid remineralization using a fluoride/saliva system for sustaining the microenvironment $\mathrm{K}_{\mathrm{FAP}}$ levels has been examined in vivo. Micronized $\mathrm{CaF}_{2}$ applied with a cellulose film was the fluoride source which, together with salivary phosphate and calcium, provided the necessary thermodynamic driving force for the remineralization process. The results of the in vivo experiments together with earlier in vitro data show that relatively high levels of fluoride (in the form fluorapatite or fluorhydroxyapatite) at substantial depths ( $\sim 50$ microns) may be deposited in a relatively short period of time $(\sim 24-48 \mathrm{hrs})$.

\section{REFERENCES}

1. BRUDEVOLD, F.; McCANN, H.G.; NILSSON, R.; RICHARDSON, B.; and COKLICA, V.: The Chemistry of Caries Inhibition Problems and Challenges in Topical Treatments, J Dent Res 46:37-45, 1967.

2. RICHARDSON, B.: Fixation of Topically Applied Fluoride in Enamel, Ann NY Acad Sci 153:20-50, 1968; J Dent Res 46:87-91, 1967.

3. MELLBERG, J.R.; LAAKSO, P.V.; and NICHOLSON, C.R.: The Acquisition and Loss of Fluoride by Topically Fluoridated Human Tooth Enamel, Arch Oral Biol 11: 1213-20, 1966. 
4. MELLBERG, J.R.; NICHOLSON, C.R.; and LAAKSO, P.V.: The Effect of a Barrier Coating on Fluoride Uptake by Human Tooth Enamel, Arch Oral Biol 12:1177-87, 1967.

5. PUGNIER, V.A.: Cyanoacrylate Resins in Caries Prevention: A Two-year Study, JADA 84:829-35, 1972.

6. BUONOCORE, M.G.: Adhesives in the Prevention of Caries, JADA 87:1000-1005, 1973.

7. DOGON, I.L.; VAN LEEUWEN, M.; and KIRKLIN, M.: In vivo Studies of the Sealing of Fluoride in Teeth: Two-year Clinical Results, IADR Progr \& Abst 52:No. 293, 1973.

8. KOCH, G. and PETERSSON, L.G.: Fluoride Content of Enamel Treated with a Varnish Containing Sodium Fluoride, Odont Rev 23:437-46, 1972.

9. STAMM, J.W.: Fluoride Uptake from Topical Sodium Fluoride Varnish Measured by an in vivo Enamel Biopsy, Canad Dent A J 40: 501-4, 1974.

10. PETERSSON, L.: In vivo Fluoride Uptake in Human Enamel Following a Treatment with a Varnish Containing Sodium Fluoride,
Odont Rev 26:253-66, 1975.

11. PETERSSON, L.: Fluoride Gradients in Outermost Surface Enamel After Various Forms of Topical Application of Fluorides in vivo, Odont Rev 27:25-50, 1976.

12. MELLBERG, J.R.; NICHOLSON, C.; MILLER, B.; and ENGLANDER, H.: Acquisition of Fluoride in vivo by Enamel from Repeated Topical Sodium Fluoride Applications in a Fluoridated Area: Final Report, $J$ Dent Res 49:1473-7, 1970.

13. MELLBERG, J.R.; NICHOLSON, C.; MILLER, B.; and ENGLANDER, H.: Fluoride Uptake in vivo from Mouthpiece Applications of Acidulated Phosphate Fluoride Gel in a Fluoridated Area, IADR Progr \& Abst 51: No. $181,1972$.

14. YONESE, M.; FOX, J.L.; and HIGUCHI, W.I.: Fluoride Remineralization of Demineralized Hydroxyapatite and Bovine Tooth Enamel, IADR Progr \& Abst 57:No. 50, 1978.

15. YONESE, M.; ABRAHAMS, L.; FOX, J.L.; HIGUCHI, W.I.; and CHARBENEAU, G.: Novel Fluoride Topical Delivery System for Remineralization, IADR Progr \& Abst 58: No. $1114,1979$.

\section{INTERNATIONAL CONFERENCE ON ORAL SURGERY 23-26 JUNE 1980 TRINITY COLLEGE, DUBLIN}

SYMPOSIUM A. FACIAL PAIN

CHAIRMAN: PROF. D. POSWILLO

SYMPOSIUM B. OSTEOMYELITIS OF THE JAWS

CHAIRMAN: MR. N. ROWE

WITH PANELS OF INTERNATIONAL REPUTE

THE SECRETARIAT, VII I.A.O.S. CONFERENCE, 12 PEMBROKE PARK, DUBLIN 4, IRELAND. 